\title{
A ESCRITA DE EDUARDO MILÁN E SEU DIÁLOGO COM O CONCRETISMO
}

\author{
Claudia Dias Sampaio
}

\begin{abstract}
RESUMO
Por ser um marco na história da poesia brasileira e por sua projeção internacional, o Concretismo continua sendo foco de interesse de pesquisas sobre sua recepção tanto no panorama da poesia contemporânea no Brasil quanto no exterior. Neste estudo, analisaremos um prisma dessa recepção, a partir do diálogo entre a escrita de Eduardo Milán e as propostas teóricas e críticas dos poetas concretos.
\end{abstract}

PALAVRAS-CHAVE: Poesia contemporânea; Concretismo; México.

"Escribir es desnudarse, escribir es vestirse" (Errar, Milán, 2012).

\section{Introdução}

irar completamente a roupa, estar nu, descoberto, então começar a colocar peça por peça de uma vestimenta, proteger o corpo, abrigarse. Um ato cotidiano que pode tomar densidade de metáfora poética quando colocamos atenção: a) ao descobrir-se, b) ao intermezzo - o encontrar-se nu (diante de um espelho, de si, do outro?), c) e à escolha cuidadosa da vestimenta, que vai disfarçar, encobrir esse corpo. Essa atenção implica a consciência do jogo entre revelar e ocultar e também a humildade diante da ruína irreversível que nos impóe o passar do tempo. Podemos assim aproximar o verso de Milán, que abre este texto, ao que formulou Marcos Siscar sobre a dificuldade da escrita: "Escrever é um desafio porque a escrita pressupóe 
resolvida a questão da soberania do sujeito: ela se nutre dos falsos paraísos da sinceridade" (SISCAR, 2007).

Está, portanto, no cerne dessa discussão a problemática do sujeito e o que ela aporta como matéria imprescindível: a imaginação. Afinal, para a construção de "falsos paraísos da sinceridade" é preciso um consistente trabalho de imaginação. E empreendê-lo significa mover-se de um modo significativamente adverso à avalanche de informaçôes e imagens nas quais estamos continuamente imersos. Nesse contexto, definitivamente, escrever é um desafio, e escrever poesia ainda mais, já que esse tipo de discurso exacerba a problemática do sujeito.

Enquanto os autores de narrativa atualmente se debatem com a lacuna de sobre o quê escrever, na poesia essa luta se deflagra na relação com a tradição (que peças da vestimenta usar, combinar ou descartar). O ponto crucial do conflito, dessa desconfiança em relação ao passado $^{1}$, seria o cenário de uma polarização estética e política, evidenciado pela dicotomia entre uma poesia que valoriza a experiência vivida e outra que privilegia a experimentação formal; efeito da herança concretista e dos desacordos gerados pelo movimento cujo estopim foi a ruptura de Ferreira Gullar e a posterior criação do Neoconcretismo.

Confesso defensor dos poetas do Concretismo, Luiz Costa Lima apontou, no entanto, o efeito dicotômico provocado por esse movimento como um problema incontestável: "um dos riscos que corre todo movimento de vanguarda, mesmo quando, como é o caso presente, as condiçóes sócio históricas o impedem de seguir o monolítico da lógica militar, consiste em dividir maniqueísticamente o mundo" (COSTA LIMA, In.: SÜSSEKIND E GUIMARÃES, 2004, p. 119).

Mas apesar da rigidez das polarizaçóes, as análises empreendidas a partir da distância do tempo e da transformação dos paradigmas permitem reflexóes mais depuradas. Por exemplo, ainda que os Concretistas defendessem por via teórica o poema como "objeto em e por si mesmo, não um intérprete de ob-

1 Em "A cisma da poesia brasileira" (2005) Marcos Siscar apresenta a hipótese de que há um impasse em relação à herança da história recente da poesia no Brasil. O comentário se dirige em especial ao Concretismo, "geração extremamente fértil em ideias sobre a poesia", silenciada pelos poetas dos anos 1990 que encontraram seus diálogos poéticos com o cânone modernista (SISCAR, 2005, 46). 
jetos exteriores e/ou sensações mais ou menos subjetivas" (CAMPOS et al., 2006, p. 216), há em alguns poemas de Augusto de Campos a presença de uma subjetividade aliciante, como bem observaram Julio Castañon Guimarães ${ }^{2}$ e Eduardo Sterzi em seus ensaios que integram o livro Sobre Augusto de Campos (2004), organizado por Flora Süssekind e Julio Castañon Guimarães.

Em "Todos os sons, sem som”, Eduardo Sterzi questiona se a formulação "objeto em e por si mesmo" não seria "o primeiro estágio da constituição de uma nova figura do sujeito” (STERZI. In.: SÜSSEKIND e GUIMARÃES, 2004, p. 109). Ainda que por sua negação, a questão da subjetividade constitui, portanto, parte do legado dos poetas concretos.

Mas afinal, "Em que tem consistido a lição dos concretos?” A pergunta apresentada por Luiz Costa Lima em "Os nervos da nova anatomia” (1996) é um dos leitmotivs deste estudo, cuja proposta é refletir sobre a escrita de Eduardo Milán e seus diálogos com os poetas Concretos.

Eduardo Milán nunca escreveu poemas concretos, mas no entanto dialoga com as propostas críticas e teóricas desse movimento da vanguarda brasileira.

Entre as propostas teóricas e críticas mais potentes geradas pelo Concretismo podemos destacar: 1) A teoria da tradução de Haroldo de Campos (transcriação); 2) As intervençôes no cânone, trazendo para a cena literária autores como Sousândrade e Oswald de Andrade; 3) A tradução e difusão no Brasil de poetas estrangeiros fundamentais na história da Literatura universal, como por exemplo: Joyce, Pound e Homero; 4) E, finalmente, o incremento na discussão da questão da subjetividade.

Quando Eduardo Milán chegou ao México, o Concretismo brasileiro já havia sido difundido, sobretudo a obra de Haroldo de Campos, pela conexão com Octávio Paz. Milán esclarece que quase não se teve notícias de toda a discussão levantada por Ferreira Gullar, pouco se sabe, até hoje, sobre o Neoconcretismo e, inclusive, as obras de Décio e Augusto, tiveram pouca, ou nenhuma, difusão no México.

2 Em "Alguns lances de escrita”, Castañon analisa as dimensôes claramente biográficas de poemas como "roland" (1980), cujo título é o nome de um dos filhos do poeta e ressalta que não está ausente dessa poesia a "problematização do sujeito" (SÜSSEKIND e GUIMARÃES, 2004, p. 76). 
O oficial daqui foi a recepção dada por Octávio Paz à obra de Haroldo, nem tanto Augusto e muito menos Décio. Do ponto de vista da recepção, a obra de Décio era de alguma maneira um problema de incomunicabilidade da linguagem poética. Ele era o mais distante em relaçáo ao que pode receber uma poesia ortodoxa como a mexicana, muito normativa em seu tratamento da linguagem, enquanto ao que pode ser uma busca de linguagem que comunica diretamente com o incomunicável poético. E Décio é o mais incomunicável dos poetas da tríade concreta. Ele não podia entrar (MILÁN, 2014).

\section{A recepção imediata do concretismo no México}

Durante as décadas de 1960 e 1970, vários poetas mexicanos trabalharam a partir dos postulados do Concretismo, especialmente do grupo Noigandres, como ficou mais conhecido o Concretismo brasileiro no exterior. O ponto de partida é o primeiro encontro-exposição da poesia concreta no México, organizado em 1966 por Mathias Goeritz. O encontro aconteceu na galeria Aristos, da Universidad Autónoma de México (UNAM), reuniu obras de 51 artistas de diferentes países e apresentou conferências de Max Bense e de Eugen Gomringer. Os artistas Mathias Goeritz e Vicente Rojo foram os representantes do México.

Poeta, arquiteto, artista plástico e historiador da arte, Mathias Goeritz realizou nessa época poemas concretos em papel e nos muros da Cidade do México. Também foi durante a década de 1960 que Octávio Paz publicou Blanco, os Topoemas e Discos visuales. E Ulises Carrión escreveu sobre a espacialidade como parte de sua poética em El arte nuevo de hacer libros, publicado no México e na Alemanha. Na década seguinte, Jesús Arellano publicou El canto del gallo e Poelectrones e Montes de Oca apresentou Lugares donde el espacio cicatriza (cf.: LEYVA, 2012). Nos anos 1980, logo após o trágico episódio do terremoto de 1985 que traumatizou o país, aconteceu a primeira edição da Bienal Internacional de Poesia Visual e Alternativa.

Nesse momento da recepção do Concretismo no México o que vemos é uma valorização do conceito "verbivocovisual", cuja dimensão visual se conecta de imediato com a intensa difusão das artes visuais nessa cultura, que se 
apresenta nas ruas, nas instituições e no imaginário do povo mexicano a partir principalmente da tradição muralista no México.

\section{Eduardo Milán: um leitor do concretismo}

Eduardo Milán é um poeta e crítico cuja obra ganha cada vez mais notoriedade no contexto da poesia contemporânea internacional. Os poemas de Milán são poemas críticos e seu interesse está claramente voltado para a produção de uma poesia que problematize, questione o sujeito, o mundo. Por isso, o interesse em estudar sua obra e difundi-la no Brasil, onde ainda é pouco conhecida.

Milán nasceu no Uruguai e as consequências da ditadura militar naquele país o levaram ao México, onde vive desde 1979. O pai havia sido preso por razóes políticas. No México estavam alguns amigos uruguaios, também exilados políticos, como Henrique Ferro. Esses amigos o receberam e assim ele começou a entrar em contato com o mundo cultural e intelectual do México. Escrevia ensaios e fazia traduçóes para o suplemento literário La letra y la imagen, dirigido pelo poeta mexicano Eduardo Lizalde e pelo espanhol José de la Colina. Em 1986, quando a situação política já estava mais amena, finalmente voltou ao Uruguai. Mas no México estava a filha, Leonora, e ele então retornou ao país para construir sua vida. Nesse período, recebeu um convite de Octávio Paz para trabalhar como secretário de redação na Revista Vuelta. Primeiramente Milán não aceitou, então Paz propôs que ele fizesse uma coluna sobre poesia, com liberdade para escolher os temas sobre os quais ia escrever. "Naquele momento o México era um país completamente autorreferente e eu pude oferecer algo que não havia, uma visão do que estava ocorrendo no presente no panorama da poesia latino-americana" (MILÁN, 2014). Os textos escritos durante dois anos foram reunidos em Una cierta mirada (1989).

A língua portuguesa é herança da mãe, brasileira, que morreu quando ele tinha apenas um ano e meio. Mas ele sempre manteve os laços com a família materna e com o português. A poesia brasileira chegou pelo ouvido, "porque eu tenho um certo sentido musical forte, talvez vindo dos negros uruguaios, do candombe. Então comecei a conhecer alguns 'poetas da música', como Chico Buarque e Caetano Veloso, e por aí cheguei na poesia Concreta” (MILÁN 2014). 
Por Octávio Paz, Milán conheceu Haroldo e os dois tiveram uma relação de amizade que se fortaleceu em encontros em São Paulo e na Cidade do México. Sobre o poeta brasileiro Milán escreveu: "Haroldo de Campos é, na América Latina, o poeta pensador que conseguiu manter vivo o espírito das vanguardas durante o decorrer de toda a metade do século 20" (MILÁN 2003).

Outro diálogo de Milán com o Concretismo brasileiro reflete-se na homenagem a Augusto de Campos em seu empenho de traduzir o poema "Elegy: going to bed" (Indo para o leito), de John Donne. O poema ganhou popularidade na cultura brasileira pela música "Elegia", que Caetano Veloso fez a partir de seus versos: "Deixe que minha mão errante adentre, atrás, na frente, em cima, em baixo, entre/ Minha América, minha terra à vista...”).

Ao expor um paralelo, como se tratasse de dois poemas, um de Donne e um de Augusto, o poema de Milán sobre Augusto de Campos chama a atenção justamente para esse elemento de criação poética do tradutor de poesia. $\mathrm{O}$ poeta recolhe a expressão "urdidura subjacente", para apresentar o movimento de tessitura na poema traduzido por Augusto que, implicitamente, vai sendo construído à sombra do poema de Donne.

Él tiene - Augusto - una expresión que califica

lo suyo, lo de Donne: "la urdimbre bubyacente"

traba no que traba - tábano que jode

pueblos enteros dando alrededores

al vacío que liga por zumbido -

sino que enlaza, anuda, teje

un enmadejamiento

hoy donde a flor de piel se exponen garra y llaga

garra y llaga en flor

rallada flor

Augusto urde y muestra: prueba es la urbe

que no deja especular más espectáculo

eso que por lluvia riela arriba es por espejo de espaldas real abajo

Donne es distinto: donde urdir era el acto que sostiene

el andamiaje de la dama en cuerpo entero

pone pelos en la lengua, no en la piel 
son con color los dos sonidos

el que urde y el que urbe, rojos (MILÁN, 2008, p. 89). ${ }^{3}$

Augusto de Campos traduziu ao todo onze poemas de John Donne. E a escolha dos autores sobre os quais escrevemos ou traduzimos também é de alguma forma parte de nossa escritura. Assim, ao escolher o poeta metafísico inglês do século XVII, John Donne, Augusto se afirma como leitor de T.S. Eliot, quem primeiro empreendeu o resgate dos poetas metafísicos ingleses do século XVII, mostrando as relações entre a poesia deles e a dos pós-simbolistas franceses, em "The metaphysical poets" (1921) e de Ezra Pound, em sua concepção de tradução como crítica e criação (de onde parte Haroldo para desenvolver seu conceito de "transcriação"). Há ainda a aproximação aos aspectos mais característicos dos metafísicos: "concentração, concisão e conceito" (cf.: SOUZA, 1997) com a poética de um autor fundamental para o Concretismo: João Cabral de Melo Neto.

\section{João Cabral: possibilidade de outras leituras do concretismo}

Em Resistir, livro de ensaios sobre poesia, no texto de abertura, "Aclaración”, Eduardo Milán cita João Cabral de Melo Neto para falar sobre a

3 Ele tem - Augusto - uma expressão que qualifica

o que é seu, o que é de Donne: "a urdidura subjacente"

trava no que trava - tedioso que arruina

cidades inteiras espalhando pela vizinhança

o vazio que conecta por zumbido -

se não enlaça, une, tece

uma urdidura

hoje onde à flor da pele se expóem garra e chaga

garra e chaga em flor

ferida flor

Augusto urde e mostra: prova é a urbe

que nâo deixa especular mais que espetáculo

isso porque a chuva que brilha acima é pelas costas do espelho real de abaixo

Donne é diferente: onde urdir era o ato que sustenta

$\mathrm{o}$ andaime da dama no corpo inteiro

póe pelos na língua, não na pele

são com cores os dois sons

o que urde e o que urbe, vermelhos. (Esta, e a dos seguintes poemas, são traduçóes minhas.) 
necessidade de escrever: "escribir solamente cuando ya no se puede más (dejar de escribir)" e completa dizendo que, no entanto, isso não garante nenhuma graça especial. Uma vez que a angústia incontrolável é superada, "nos vuelve otra vez ciudadanos democráticos". E em todo caso, "nadie puede plantearse seriamente la necesidad de la escritura poética desde la necesidad que tiene el mundo de la poesía" (MILÁN, 2004, p. 9). Ainda no texto "Aclaración”, Milán desenvolve uma reflexão bastante pertinente sobre o trabalho do poeta no contexto latino americano. Segundo ele, Un coup de dès não nasceu na América Latina, pois não havia a necessidade de que esse tipo de poema fosse escrito aqui, pois ninguém queria a referência dessa ausência. Ele lembra como exceção o amor dos poetas concretos ao poema de Mallarmé e justifica esse amor pelo fato de que se tratava do último movimento de vanguarda, "o sea, de la última tentación de reingreso al espíritu universal”. A necessidade que Milán observa na América Latina, é uma necessidade de esperança, pois aqui os temas são sempre: "el hambre, la discriminación, la intolerancia, la represión, los modelos imposibles de crecimiento, los niños dejados a la buena del destino”. Para ele, não há uma grande necessidade de busca da palavra original, da purificação poética. "Aquí la palabra poética no busca la originalidad como proyecto. Es muy arduo el camino de vuelta. Si sucede es por epifanía. Aquí la palabra poética es inmediata. Yo escribo por todo eso" (MILÁN, 2004, p. 11).

Isso nos faz pensar na poética de João Cabral de Melo Neto, poeta ainda pouco difundido no México. Ele também escrevia por tudo isso, mas sempre manteve a preocupação em construir um projeto poético, empreendeu, a seu modo, a busca da palavra original, "da purificação poética". Combatia a ideia que relaciona poesia à inspiraçáo e ao acaso, o que o levou a elogiar a dimensão crítica das propostas concretistas, que a seu ver era um modo de ir contra a ideia de que para escrever era preciso "baixar um santo" (MELO NETO, 1988).

Desde o primeiro livro, Pedra do sono, em 1942, o poeta se preocupou em construir uma obra poética singular, pela precisão das formas expressivas e pela escolha dos temas do seu discurso poético, numa produção que se estendeu até os anos de 1990.

João Cabral construiu uma poesia dirigida ao intelecto, sem sentimentalismo, mas com uma profunda conexão com seu espaço interno (sua subjetividade) e com o contexto em que vivia. Seu projeto poético é constituído por 
uma poesia crítica, de rigor formal, que dialoga com as artes plásticas (Miró, Mondrian), com uma atenção constante à dimensão visual do poema.

O engenheiro (1945) foi um marco na história da Literatura brasileira, uma espécie de divisor de águas entre a poesia da geração de 45 e o Concretismo, que tomou essa obra por referência.

Esse viés do Concretismo, da dimensão crítica da linguagem - que não está tão atrelada ao sentido "verbivocovisual", mas a um trabalho que busca conjugar subjetividade, contexto histórico e reflexão sobre a própria linguagem - cuja uma das fontes é o encontro com a poética cabralina, parece não ter sido a herança mais marcante na recepção do Concretismo. A difusão do caráter "verbivocovisual" teve uma difusão mais ampla, principalmente quando pensamos na recepção imediata do Concretismo brasileiro no México, com Mathias Goeritz e os poemas concretos, os poemas murais, "Blanco", de Octávio Paz, e em seus diálogos com Haroldo de Campos que traduziu o poema de Paz e o publicou, "Transblanco", onde inseriu uma série de textos, inclusive correspondências com o poeta mexicano, criando assim uma nova obra. E na poesia visual que já se tornou uma tradição nas sucessivas bienais que aconteceram no México a partir de 1985.

Uma das hipóteses que podemos levantar para esse fato é a pouca difusão da poética de João Cabral e de suas relações com o Concretismo. E ainda, na pouca difusão das obras de Augusto e Décio, conforme relatou Milán.

A valorização desse aspecto de questionamento da linguagem, e o que ele carrega, como a problematização da subjetividade, tem por consequência a produção de uma poética da tensão, que ultrapassa as discussóes dicotômicas: ou apresenta a tensão mesmo dos processos de transformaçóes dos paradigmas e valores que já não bastam no mundo atual e, conjugando experiência vivida e experimentação formal, dialogam com a História e com a tradição da Literatura.

Podemos ler essa "poética da tensão" no poema que abre o livro Errar:

$\mathrm{Ni}$ arco ni flecha: solo

tensión. Casi se diría Oriente

donde la ciencia del pájaro no se enciende a mediodía. Ni pájaro ni plumas:

sólo el encendido fuego. Debajo 
del pájaro, debajo del tajo del mediodía

esta herida no se cierra por encendida,

por empecinada nada, por el puro eco

de una cara a otra cara. Por carente. ${ }^{4}$

Outro poema, do mesmo Errar, cujo um dos versos é nossa epígrafe, apresenta de modo contundente a reflexão que abre este texto. Nele, a imagem da ferida se evidencia no jogo com os vocábulos "ferir", "ferida", "referir".

Me refiero a ti como a dos fieras porque una herida son dos fieras. Hay que estar muy herido para referirse, muy herido de lenguaje.

Ao escolher suas "vestes", o poeta nos fala do abismo da morte de Cristo e traz a abissal imagem do Grand Canyon, em espanhol conhecido como Canon del Colorado. Uma profundidade abismal, um templo vazio, desértico: peças de sua vestimenta. A esse templo vazio, desértico, se soma o visceral, o sangue, o pássaro de sangue, em uma possível alusão à tradição da poesia inglesa (Yeats e Wilde).

Me refiero al Cañon del Colorado. Me refiero a un abismo desnudo que Christo viste, en la aurora lo veo en su cresta. Me refiero a la nada, al punto opuesto donde está Christo. Escribir es desnudarse, escribir es vestirse. Pero el vértigo no viste, viste el rojo, el pájaro de sangre, el gorjeo del pájaro de sangre en Inglaterra: pío, pío. La que te cubre no cobra por vestirse. Ella, la

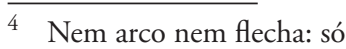
tensão. Quase Oriente onde a ciência do pássaro não arde ao meio-dia. Nem pássaro nem penas: só o fogo ardente. Debaixo do pássaro, debaixo do cortante do meio-dia esta ferida não se fecha por acesa, por teima nada, pelo puro eco de uma cara a outra cara. Por carente. 
doncella leve que sobre ti se deposita, esposa del esposo, gemela del gemido. Por último, sin miedo, me refiero a mí. ${ }^{5}$

O "eu" ao qual o poeta se refere, o traço autobiográfico, carrega a ferida, uma abertura, algo inconcluso. O que de certo modo entra em conexão com a ideia de que vivemos em uma época de transformação dos paradigmas, de um processo, apontado por Siscar no contexto da poesia contemporânea brasileira (SISCAR, 2005), mas que poderíamos expandir para esse caso da escrita de Milán. Para desconstruir a "soberania do sujeito" é preciso então romper, abrir uma ferida, em si, na linguagem, disso também nos fala o poeta, de uma linguagem que reflete essa ferida aberta. Por fim, o que se apresenta como sendo autobiográfico: "Por último, sem medo, me refiro a mim", se relaciona com os versos anteriores, e nos faz pensar nas relaçôes entre poesia e mercado, "a que te cobre não cobra por vestir-se", uma referência à prostituição, em seguida conformada na figura da "esposa do esposo".

Expor enfim as discussóes da ordem subjetiva e da ordem do mundo no qual está inserido seriam pautas eleitas por um poeta interessado em construir uma poesia crítica, aquela que expóe a ferida, na linguagem. Quando questionado sobre o que é um poeta crítico, Milán fala do problema da poesia contemporânea no México, inserida numa espécie de "culto aurático", onde há uma cisão entre a História e a vida. Segundo ele, o que se apresenta, em geral, é a preocupação dos poetas em fazer poesia para o cânone, para a classe

5 Me refiro a você como a duas feras porque

"ma ferida são duas feras. É preciso estar

${ }^{m}$ uito ferido para referir-se, muito ferido de linguagem.

$\mathrm{M}_{\mathrm{e}}$ refiro ao Grand Canyon.Me refiro a

${ }^{\mathrm{u}} \mathrm{m}$ abismo despido que veste Cristo, na

${ }^{a}$ urora o vejo em sua devastação. Me refiro ao nada,

${ }^{\mathrm{a}}$ o ponto oposto onde está Cristo. Escrever é

despir-se, escrever é vestir-se. Mas a vertigem

não veste, veste o vermelho, o pássaro de sangue, o

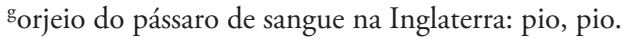

${ }^{\mathrm{A}}$ que te cobre não cobra por vestir-se. Ela, a

d onzela leve que sobre você de deposita, esposa do

'sposo, gêmea do gemido. Por último,

sem medo, me refiro a mim. 
dominante, para "as oligarquias culturais latino-americanas". Nesse sentido, a proposta de uma poesia crítica seria um comprometimento com a vida, com o mundo, com a "dívida humana que a América Latina tem com o próprio desenvolvimento da espécie, que se comparado com outras civilizações, é espantoso" (MILÁN, 2014). Contudo, ele reconhece o quão difícil é esse tipo de produção no atual contexto social e político do México:

Chega um momento em que a senhorita do governador, ou da presidência de não sei o quê dizem que não entendeu seu poema. Está certo os poemas não são para eles... O que acontece é uma espécie de entrevero e de superficialização do que foi algo realmente importante. A vanguarda do princípio do século 20 foi um momento fundamental na história da arte e na história do homem, como foram fundamentais os movimentos dos projetos revolucionários abortados (MILÁN, 2014).

A imagem da ferida, na linguagem, nos faz pensar não somente em dor e na dificuldade de romper a soberania do sujeito, mas traz também algo de cáustico, de desolador, as vestes abismais que sugerem o poema de Milán. Faz pensar no texto de Adorno sobre Heine, quando ele diz que a ferida de Heine está em sua lírica: na "mediação entre a arte e o cotidiano desprovido de sentido" (ADORNO, 2003, p. 129). Contudo, há nesse cenário cáustico algo da ordem de uma potência que se mantém acesa com escritas como a de Milán, que ultrapassa o reflexo de uma época de processo, de transformação de paradigmas, mostrando, sim, os contornos de tempos ardentes, onde se torna imprescindível assumir riscos, comprometer-se com a vida, posicionar-se, com coerência, política, social e artisticamente.

\section{Referências}

ADORNO, Theodor W. "A ferida Heine". Notas de Literatura I. São Paulo: Duas Cidades, 34, 2003.

CAMPOS, Augusto, CAMPOS, Haroldo, PIGNATARI, Décio. Teoria da poesia concreta. $5^{\text {a }}$ ed. Cotia, SP: Ateliê editorial, 2006.

CAMPOS, Haroldo. Metalinguagem e outras metas. São Paulo: Perspectiva, 1982. 
LEYVA, Cinthya García. El concretismo en México: dos ejemplos de Mathias Goeritz. Periódico de poesía da UNAM. Número 49, maio de 2012. http:// www.periodicodepoesia.unam.mx/index.php?option=com_content\&task=view\&id=2318.

MELO NETO, João Cabral de. Entrevista a Toni Marques. O Estado de S. Paulo. Caderno 2. São Paulo, 17 de set., 1988.

MILÁN, Eduardo. Entrevista realizada, em Coyoacán, Cidade do México. Gravada pela equipe: Gala Lutteroth, Santiago Lirola, Francisco Kochen e Claudia Sampaio. Novembro de 2014.

MILÁN, Eduardo. Disenso. Ciudad de México: Fondo de Cultura Económica, 2008.

MILÁN, Eduardo. Resistir: Insistencias sobre el presente poético. Ciudad de México: Fondo de Cultura Económica, 2004.

MILÁN, Eduardo. Errar. Cidade do México: Aldus, 2012.

MILÁN, Eduardo. El odiseo brasileño. El País Cultural. 31 de outubro de 2003.

http://letras-uruguay.espaciolatino.com/aaa/campos/odiseo_brasileno.htm

SISCAR, Marcos. "A cisma da poesia brasileira”. Revista Sibila, ano 5, n. 8-9, São Paulo, 2005.

SISCAR, Marcos. "Responda, cadáver": o discurso da crise na poesia moderna. Alea, vol.9, n.2, 2007. Em: http://www.scielo.br/pdf/alea/v9n2/ a03v09n2.pdf

SOUZA, Ana Helena. Donne, Augusto de Campos e a tradução criativa. Revista USP. São Paulo (34): 134-150, jun./ago., 1997.

SÜSSEKIND, Flora e GUIMARÁES, Julio Castañon (Org.). Sobre Augusto de Campos. Rio de Janeiro: 7 Letras e Casa de Rui Barbosa, 2004. 


\title{
THE WRITING OF EDUARDO MILÁN AND YOUR DIALOGUE WITH CONCRETISM
}

\begin{abstract}
The Concretism is a reference in the history of Brazilian poetry and its international projection, from the $1950 \mathrm{~s}$ to the present day, remains the subject of research about your reception at the panorama of contemporary poetry in Brazil and abroad. In this study we analyze one of the prisms that reception, from the dialogue between the writing of Eduardo Milan and critical and theoretical proposals of the concrete poets.
\end{abstract}

KEYWORDS: Contemporany poetry; Concretism; Mexico.

Recebido em: 30/10/2014 Aprovado em: 20/03/2015 